\title{
PSICOSES DEGENERATIVAS: FASOFRENIAS DE KLEIST
}

\author{
ROBERTo TOMCHINSKY *
}

Apesar de já decorridas mais de três décadas desde que Kleist discriminou as entidades clinicas que reuniu sob a denominação genérica de "psicoses autóctones degenerativas benignas", é de surpreender que tais quadros clínicos ainda continuem bastante desconhecidos. Em face de sua importância e tendo em vista as modificações verificadas nas classificações destas moléstias, propusemo-nos realizar uma breve revisão como tentativa de atualização dêste problema. Assim procedendo, pretendemos chamar a atenção para estas psicoses de efetiva existência clínica e para sua inegável importância em Psiquiatria.

Não obstante constituírem estas psicoses cêrca de $25 \%$ do total das chamadas psicoses endógenas, conforme foi verificado por Kleist e seus colaboradores e, em nosso meio, por Anibal Silveira e col.8, 11, 12, 13, verifica-se que inúmeros quadros clínicos psicóticos que aí deviam figurar, continuam sendo rotulados com diagnósticos de conteúdo vago e discutível, como sejam as chamadas psicoses agudas, "bouffées delirantes", episódios ou surtos em personalidades psicopáticas.

A confusão que decorre da inclusão de tais psicoses no grupo da esquizofrenia não implica sỏmente no comprometimento do prognóstico, mas repercute também em outros setores da investigaçāo clínica, psicopatológica e, até mesmo, nos tratamentos. Contribui não só para falsear em grande parte a avaliação estatística das entidades nosográficas como também influi na valorização dos recursos terapêuticos. Daí o conceito muito discutível e duvidoso das chamadas "esquizofrenias curáveis". Cabe assinalar, no entanto, que o diagnóstico de esquizofrenia pressupōe, em geral, um decurso desfavorável, mesmo no caso de admitir-se a existência de formas mais benignas.

Não obstante a existência de sintomas comuns às psicoses degenerativas e às esquizofrenias sensu latu, estas caracterizam-se essencialmente por uma decadência e embotamento por tal forma particular que as torna completamente distintas daquelas. Supomos que estas considerações pōem claramente

* Do Hospital Psiquiátrico de Vila Mariana, São Paulo. Ex-psiquiatra do Hospital de Juqueri. 
de relevo a necessidade com que se defronta o psiquiatra em tornar mais seguro o diagnóstico psiquiátrico, o qual deve ser "tão completo, tão preciso e tão objetivo quanto o diagnóstico neurológico" (Aníbal Silveira ${ }^{10}$ ).

Antes de expor os critérios para identificar e classificar as psicoses degenerativas, torna-se necessário determinar sua posição no grupo das psicoses endógenas.

Já Kraepelin, ao estabelecer a sistemática dos grandes grupos de psicoses endógenas típicas - epilepsia, esquizofrenia, psicose maniaco-depressiva e mais a histería e a paranóia - pôde verificar a existência de vários quadros clinicos que ai não podem ser englobados. Assim, separou aquêles quadros que designou como "estados mistos maniaco-depressivos" que, segundo vários autores, seriam a fonte das psicoses atipicas, embora, segundo Kleist ', inúmeras delas estariam bem distantes das manifestaçoes fundamentais do grupo maniaco-depressivo. Outros autores utilizaram o critério de considerar estas psicoses como mistura de formas tipicas, isto é, seriam elas formas mistas, por exemplo, da psicose maníaco-depressiva com a esquizofrenia. Nem estas tentativas nem a análise "estrutural" de Birnbaum ou "pluridimensional" de Kretschmer se mostravam eficientes para solucionar o problema dêstes quadros atipicos, pois, na grande maioria dêles, a sintomatologia surge como "algo unitário e autóctone". Apesar destas caracteristicas, Kleist considerou de início que não se justificava evitar a comparação destas psicoses com os quadros típicos, pois muitas formas têm parentesco com esta ou aquela psicose principal, seja pela concordância entre manifestações parciais de ambos os quadros, seja pela base constitucional em que evoluem ou, ainda, somente por afinidades heredo-biológicas. As psicoses atípicas seriam, pois, segundo Kleist, em parte colaterais ou marginais em relação ao grupo maníaco-depressivo, paranóia e epilepsia. Em certos casos, existem relações sintomatológicas e heredológicas com duas ou mais psicoses típicas e, em outras acasiōes, não é possivel demonstrar a relação estreita com qualquer grupo principal. Kleist afirma que utilizou o critério de aproximação dos processos mórbidos atípicos aos grupos principais, por motivos práticos e históricos, a fim de conseguir ordem provisória neste setor, pois não estava estabelecido de modo absoluto que tôdas as psicoses atípicas devessem ter relações de parentesco com as grandes entidades nosológicas.

Individualizado, pois, êste grupo de doenças atípicas benignas, em parte marginais às grandes psicoses endógenas, surgiu o problema de sua denominação. Inicialmente, Kleist chamou êste grupo de "psicoses autóctones constitucionais" para, ulteriormente, aceitando a denominação de Schröder, mudar a designação para "psicoses auctótones degenerativas benignas" ou, simplesmente, psicoses degenerativas. Kleist adotou o critério de utilizar um nome coletivo para designar o grupo das psicoses atipicas, prevendo que esta necessidade desapareceria quando estas diversas formas estivessem perfeitamente individualizadas e suficientemente descritas e, portanto, denominadas de modo aceitável para todos.

Deve ser lembrado que o conceito de degeneração de Kleist é totalmente diverso do da escola francesa. As psicoses degenerativas não constituem, para Kleist, moléstias com elevado grau de degeneração hereditária. Bem ao contrário, elas seriam expressão de um processo degenerativo dos genes 
patológicos, mediante somação e atenuação dos sintomas das várias psicoses típicas, fenômeno que representaria "automelhoramento da espécie". $A$ degeneração seria, pois, para Kleist, uma atenuação da morbilidade genética, que então, não desencaderia psicoses progressivas tipicas, mas, sim, psicoses de caráter benigno e decurso fásico.

O quadro 1 ilustra com clareza os caracteres gerais das aludidas psicoses, em confronto com os demais agrupamentos psicóticos.

\begin{tabular}{|c|c|c|c|}
\hline Decurso & típico & atípico & ocasional \\
\hline Situação nosogräfica & principal & colateral & esporádica \\
\hline Tipo mórbido & autóctone & $\begin{array}{l}\text { autóctone, } \\
\text { degenerativo }\end{array}$ & sintomática \\
\hline $\begin{array}{l}\text { Alteração cerebral } \\
\text { (lesional ou dinâmica) }\end{array}$ & intrinseca & $\begin{array}{l}\text { intrinseca } \\
\text { ou } \\
\text { extrinseca }\end{array}$ & extrínseca \\
\hline Fatôres neuronais & "defieit ab ovo" & $\begin{array}{l}\text { disposiçāo } \\
\text { hereditária }\end{array}$ & eventuais \\
\hline Heranca mórbida & predominante & latente & casual \\
\hline Sintomatologia & homogẽnea & heterogênea & complexa \\
\hline Evolução & $\begin{array}{l}\text { progressiva } \\
\text { ou } \\
\text { ciclica }\end{array}$ & $\begin{array}{l}\text { prolongada } \\
\text { ou } \\
\text { perídica }\end{array}$ & fortuita \\
\hline
\end{tabular}

Quadro 1 - Caracteres gerais mais comuns dos vários grupos psicóticos: dados utilizáveis para a classificação nosológica (segundo Anibal Silveira ${ }^{20}$ ).

De modo geral, tôdas as psicoses degenerativas são atípicas, benignas, de decurso fásico ou cíclico, de sintomatologia rica e variada (heterogênea), o que é admissivel pela sua heredologia de natureza mista e atenuada.

Quanto à participação cerebral, segundo Kleist 1, estas psicoses estariam subordinadas à labilidade de certos aparelhos encefálicos do tronco cerebral. Assim, determinados grupos de funções ligadas a êstes aparelhos (afetivas, psicomotoras e intelectuais), sofreriam mudanças autógenas face à labilidade constitucional que lhes seria própria (intrínsecas) ou diante de agentes patogênicos psicógenos, endócrinos ou exógenos (extrínsecos).

Vejamos, a seguir, as diversas sistematizações destas psicoses elaboradas por Kleist, detendo-nos numa descrição sumária dos respectivos quadros clínicos.

Na primeira classificação (1928), Kleist ${ }^{1}$ coloca-as ao lado dos grandes grupos nosológicos já estabelecidos, conforme se vê no quadro 2 . 


\section{FORMAS ATfPICAS}

FORMAS ATIPICAS

$\begin{array}{lll}\text { Psicoses } & \text { Confusionais } & \left\{\begin{array}{l}\text { Confusão agitada } \\ \text { Estupor }\end{array}\right. \\ \text { Psicoses da } & \left\{\begin{array}{l}\text { Forma hipercinética } \\ \text { Fotilidade } \\ \text { Forma acinética } \\ \text { Psicoses da } \\ \text { individualidade }\end{array}\right. & \left\{\begin{array}{l}\text { Hipocondria } \\ \text { Confabulose expansiva }\end{array}\right.\end{array}$

$$
\text { PSICoSES }\left\{\begin{array}{l}
\text { De inspiraçăo, aguda (expansiva) } \\
\text { Alucinose aguda (persecutória) } \\
\text { De referência } \\
\text { De "extranheza" (Entfremoung) }
\end{array}\right.
$$

EPilepsia:

PSicoses $\left\{\begin{array}{c}\text { Estados crepusculares episódicos } \\ \text { inclusive estados de "já vivido" } \\ \text { ausência com } \\ \text { perplexidade } \\ \text { Estados hipnicos episódicos } \\ \text { Impulsos mórbidos episódicos } \\ \text { (Dipsomania) }\end{array}\right.$

\section{PSICOSES CICLOIDES}

No primeiro grupo situam-se as psicoses clclóites, marginais à psicose maniacodepressiva por sua maior afinidade com as doenças circulares. Constituem elas as psicoses confusionais, as da motilidade e as da individualidade, que frequentemente evoluem por fases opostas. Assim, as psicoses confusionais assumem a forma estuporosa ou agitada, nas da motilidade se alternam a forma hipercinética e a acinética, as da individualidade manifestam-se pela hipocondria ou pela confabulose expansiva.

Psicoses confusionais - As psicoses confusionais caracterizam-se por fases de confusão (endógena) agitada e de estupor, sendo freqüente o aparecimento de desordens do pensamento, sob a forma de paralogias, e da linguagem, como parafasias.

Psicoses da motilialade - As formas hipercinéticas consistem em abundância de movimentos imotivados, sem finalidade expressiva, movimentos parasitas em curto circuito. Estas hipercinesias constituem um quadro inteiramente diverso da excitạão catatônica prọniamente dita.

Psicoses da individualidade - Constituidas pela confabulose expansiva e pela hipocondria ou depressão hipocondriaca. Na confabulose surgem producōes fabulatórias e fantásticas, que se referem às noçōes autopsiquicas; as percepçōes subjetivas correspondentes à própria identidade e ao próprio corpo também estão alteradas. Em suma, as confabulaçōes lembram o delírio de grandeza dos paralíticos gerais. 


\section{PSICOSES PARANÓTDES}

O grupo das psicoses paranóides, marginais à paranóia era constituido pela psicose expansiva de inspiração aguda, a alucinose aguda persecutória e as psicoses agudas de referência e de estranheza.

Psicose de inspiração aguda expansiva - Aparentada com a paranóia expansiva crônica, caracteriza-se por exaltacão da própria personalidade, com exagero da sociabilidade e dos sentimentos religiosos, sintomáticos dos delírios proféticos de redenção. Manifesta-se por exaltação aguda, com revelaçōes, inspiraçōes e alucinaçōes auditivas verbais, que são interpretadas como mensagens divinas. Estas psicoses têm relaçōes hereditárias e constitucionais com as doenças da afetividade, com a debilidade mental, com a epilepsia e estados epileptóides.

Alucinose persecutória aguda - Esta forma marginal à paranóia persecutória crônica teria características idênticas à alucinose alcoólica, sendo, porém, de aparecimento autóctone. Os sintomas manifestam-se como alucinaçóes auditivas e idéias delirantes persecutórias, acompanhadas, em alguns casos, de angústia intensa. Segundo Kleist', a alucinose alcoóiica representaria tendéncia constitucional a essa modalidade de psicose, nâo sendo, portanto, variedade de reação tóxica ao álcool.

Psicoses agudas de referência e de estranheza - Também aparentadas ao grupo paranóide e relacionadas ao círculo heredológico epiléptico e epileptóide, são as psicoses de referência e a psicose de estranheza (despersonalizaçāo). Estas psicoses estão condicionadas pelas alterações da categoria de referência (referència a sì). Kleist " considera a referência a si como uma manifestação psicológica normal; seria uma experiência não intelectualizada. Esta psicose caracteriza-se, portanto, por uma exaltaçāo mórbida da referida categoria, predominando na sua psicopatologia as idéias delirantes de referência.

A psicose de estranheza é caracterizada por uma diminuiçāo da categoria de referência, a qual se traduz por uma sensaçāo de estranheza, na qual as relações com o mundo estão distanciadas, sendo tudo estranho, diferente e afastado.

\section{PSICOSES EPILEPTÓIDES}

Finaimente, devem ser consideradas as formas eplleptóides, aparentadas ao grupo da epilepsia. Na classificação estão incluidos os seguintes quadros: estados crepusculares episódicos (sintomatologia idéntica ao estado crepuscular epiléptico, porém sem história convulsiva), estados de ausência com sensação do já visto e perplexidade, estados hipnicos episódicos e impulsos mórbidos episódicos.

Esta sistematização das psicoses atipicas e os respectivos quadros clínicos individualizados por Kleist, suscitou muita celeuma e, embora citadas por vários autores, entre os quais Schneider ${ }^{9}$, Lopez Ibor ${ }^{5}$, Polonio ${ }^{7}$, tem sido precàriamente acolhida pelas demais escolas psiquiátricas contemporâneas.

Prosseguindo na investigação dessas psicoses, alguns colaboradores de Kleist puderam contribuir para o esclarecimento das diversas formas clínicas. Fünfgeld dedicou-se às psicoses da motilidade e confusionais, Leonhard às psicoses de angústia e inspiração, enquanto Edda Neele ${ }^{6}$ pesquisou as bases heredológicas de tôdas essas formas atípicas, com a intenção de verificar se êsses quadros clínicos constituem sòmente sindromes de um processo patológico unitário ou moléstias independentes; Kleist inclina-se para a última hipótese. Os estudos de Leonhard 4 levaram-no a isolar a psicose paranóide de angústia e, como forma oposta, a psicose de felicidade (glück- 
psychose). Isolou ainda, como forma clínica a psicose de angústia-inspiração, correspondente à psicose delirante angustiosa-extática de Neele ${ }^{6}$. Esta autora salienta que a psicose de angústia de Leonhard aproxima-se da alucinose de Kleist. A sintomatologia de ambas seria semelhante, valorizando Leonhard a angústia como fator predominante e considerando secundárias as desordens sensoperceptivas que incidem nestes quadros.

A psicose de referência, rebatizada por Kleist como psicose angustiosa de referência (Angstliche Beziehungspsychose), em algumas ocasiões é também diagnosticada como alucinose aguda. Kleist, por sua vez, também individualizou nova forma, constituída pela psicose perplexa de significação (Ratlose Bedeutungspsychose), que se manifesta com vivências de significação, referência e perplexidade.

Em 1947, Kleist 2, revendo as suas idéias a respeito das entidades clínicas que identificou, admitindo as formas individualizadas por seus colaboradores, e não julgando mais justificável considerar essas psicoses como atípicas e inclassificáveis, resolveu reuní-las no que denominou de esferas sindrômicas de doenças episódicas e fásicas. Essas esferas têm como núcleos centrais a epilepsia e a psicose maniaco-depressiva. Esta última e as formas que lhe são paralelas constituem as psicoses fásicas ou fasofrenias pròpriamente ditas (quadro 3 ).

Psicoses bifásicas polimorfas

Psicose maniaco-depressiva (hipercinética e acinética)

Psicoses da motilidade

Psicoses confusionais (agitada e estuporosa)

Psicoses delirantes (angustiosa e extática)

Psicoses monofásicas simples

a) formas depressivas

Melancolia

Psicose de angústia

Melancolia de angústia

Psicose angustiosa de referência

Depressāo hipocondríaca

Estupor depressivo

Psicose de estranheza (despersonalização)

Psicose perplexa de significaçāo

b) formas maniformes

Mania

Psicose extática de felicidade

Psicose de inspiração

Confabulose expansiva

Excitação hipocondríaca 
Nessa classificação vemos incluídas a psicose de angústia, a psicose extática de felicidade, a psiocse de angústia e inspiração (Leonhard), denominada por Neele psicose delirante angustiosa e extática, e a psicose perplexa de significação de Kleist. A sintomatologia destas psicoses, como das demais formas, coincide perfeitamente com as respectivas denominações, dispensando, portanto, descrição pormenorizada do quadro sintomatológico.

Numa última revisão (1953), incluida na sua classificação geral das doenças neuropsiquicas, estabelece Kleist ${ }^{3}$ as esferas das moléstias fásicas com oscilações autógenas, constituídas por doenças paroxísticas e episódicas (tendo como núcleo a epilepsia) e pelas doenças fásicas ou fasofrenias (quadro 4).

1. Doenças paroxisticas e episódicas

Epilepsia genuina

Picnolepsia, narcolepsia

Impulsos episódicos (poriomania, dipsomania)

Estados crepusculares episódicos e narcolépticos

Apêndice: Psicopatía epileptóide

2. Fasofrenias

a) formas simples (unipolares):

Melancolia, psicose de angủstia, psicose angustiosa de referencia, depressão hipocondríaca, estupor depressivo

Mania, psicose extática de inspiração, excitação hipocondriaca

b) formas polimorfas (bipolares):

Psicose maniaco-depressiva

Psicoses da motilidade (hipercinética e acinética)

Psicoses confusionais (agitada e estuporosa)

Psicose angustiosa: extática de inspiraçāo

Apêndice: Psicopatía ciclóide e similares

Quadro 4 - Classificaçõo das doenças fásicas com oscilações autógenas (Kleist, 1953).

Como modificações essenciais em relação à classificação anterior, nota-se que a psicose de angústia-inspiraçāo passa a ser denominada de psicose angustiosa-extática de significação (ängstliche-ekstatische Bedeutungspsychose).

Nesta última classificação não figuram a psicose perplexa de significação (forma monofásica), a psicose de felicidade (Leonhard) e a confabulose expansiva (Kleist), sem citar a melancolia ansiosa que estaria incluída na melancolia pròpriamente dita. Quer nos parecer que as referidas formas aguardam revisão catamnéstica para serem definitivamente estabelecidas. Resta a possibilidade de constituirem a psicose de felicidade e a confabulose expansiva, variedades da mania, conforme admite Leonhard ${ }^{4}$.

Tivemos oportunidade de identificar tôdas as formas que integram esta última sistematização, predominando em nossa casuística as psicoses para- 
nóides de angústia (diagnosticadas como alucinoses persecutórias), as psicoses angustiosas de referência e as psicoses extáticas de inspiração. Concordamos com a importância dos fatôres heredológicos de linha epiléptico-epileptóide nas psicoses de inspiração, assinaladas por Kleist e confirmadas por Aníbal Silveira. Entre as formas que, segundo supomos, aguardam revisão catamnéstica, tivemos oportunidade de identificar a confabulose expansiva aguda.

Quanto à esfera das doenças paroxísticas constituídas pela epilepsia essencial e entidades epileptóides que a acompanham, parece-nos não pairar qualquer dúvida sôbre os respectivos quadros clínicos.

Em relação à sintomatologia das moléstias fásicas, torna-se importante a revisão catamnéstica, tanto a breve como a longo prazo, em face da riqueza da referida sintomatologia e com o objetivo de serem evitados descuidos diagnósticos. A presença de estados de excitação, de agitação psicomotora e de alucinações, próprias de tôdas as psicoses agudas, pode mascarar os sintomas fundamentais nos quais se baseia a identificação das entidades mórbidas. Apesar do curso benigno dessas psicoses, a remissão dos episódios é, em geral, abreviada pelas terapêuticas de choque (convulsivas e insulinica), respondendo também de modo positivo a alguns neuroplégicos.

Para terminar, devemos frizar, mais uma vez, a importância destas formas clinicas diante das pesquisas de novos recursos terapêticos em Psiquiatria. A avaliação perfeita sôbre a validade e eficácia das novas drogas que surgem dia a dia no que tange às moléstias psiquicas endógenas é extremamente dificultada à vista dos diagnósticos incorretos. Como é de verificação freqüente, os anunciados efeitos positivos de inúmeras drogas são, em parte, devidos ao desconhecimento destas formas benignas e de seus caracteres clínicos.

E de ressaltar que as particularidades heredológicas destas formas básicas estão a exigir um incremento das pesquisas genéticas, com finalidade de orientação eugênica, o que limitaria o pessimismo em tôrno das doenças mentais.

\section{RESUMO}

O autor procura resumir os estudos de Kleist e seus colaboradores referentes às psicoses degenerativas ou fasofrenias, grupo constituído por psicoses atipicas, benignas, fásicas e cíclicas, que apresentam sintomatologia rica e variada devido a seus caracteres heredológicos mistos e atenuados. A principio estas doenças foram consideradas como aparentadas aos grandes grupos endógenas - psicose maníaco-depressiva, paranóia e epilepsia - e foram classificadas como colaterais aos mesmos, por motivações práticas e históricas, como assinalou Kleist, para o qual os caracteres benignos seriam devidos à degeneração da morbilidade genética da doença.

São apresentadas as diversas sistematizaçōes dessas doenças com comentários sumários sôbre os vários quadros clínicos. 
O autor insiste na importância da identificação destas psicoses desde que representam cêrca de $25 \%$ das doenças mentais endógenas. Além disso, como remite $n$ sem deixar defeito, não devem ser confundidas com a esquizofrenia como ocorre freqüentemente. Seu diagnóstico correto evitará também exageros de apreciação quanto à eficácia de novas drogas terapêticas que dia a dia surgem no campo psiquiátrico.

\section{SUMMARY}

\section{Kleist's degeneration psychoses: phasophrenias}

The author tries to summarize the studies of Kleist and his collaborators concerning the degeneration psychoses or phasophrenias, group constituted by those benign, atypical, phasic and cyclical psychoses, presenting a rich and varied symptomatology due to their mixed and attenuated heredological characters. At first these disease were related to the great endogenous groups - maniacs-depressive psychosis, paranoia and epilepsy - and were classified as collaterals groups for practical and historical reasons as pointed Kleist, who postulated that their benign characteristics was due to a degeneration of the disease's genetical morbidity.

The author stress the importance in identifying these psychoses since they represent about $25 \%$ of the endogenous mental diseases. Furthemore, as they recover without defect, in accordance with their benign nature, they should not be mistaken with schizophrenia, as often occurs. Their diagnosis also would help in avoiding the exaggerations on the efficacity of new therapeutical drugs, that appear day by day in the psychiatric field.

\section{REFERENCIAS}

1. KLEIST, K. - Uber Zykloide, paranoide und epileptoide Psychosen und über die Frage der Degenerationspsychosen. Schwelz. Arch. 1. Neurol., 23:3-37, 1928. 2. KLEIST, K. - Progresos de la Psiquiatria. Neuropsiquiat. (Buenos Aires), 1:209222, 1950. 3. KLEIST, K. - Die Gliederung der neuropsychischen Erkrankungen. Monatsschr. f. Psychiat. u. Neurol., 123:5-6, 1953. 4. LEONHARD, K.; SOLE-SAGARRA, J. - Manual de Psiquiatría. E. Morata, Madrid, 1953. 5. LOPEZ IBOR, J. J. - Los Problemas de las Enfermedades Mentales. Ed. Labor, Barcelona, 1949. 6. NEELE, E. - Die phasischen Psychosen. J. Ambrosius Barth Verlag, Leipzig, 1949. 7. POLONIO, P. - Psicoses e reações ciclóides. Actas Luso-Españolas de Neurol. y Psichiat., 12:1-21, 1953. 8. ROBORTELLA, M. - Les psychoses dégénératives de Kleist à la lumière de la Génetique. Arq. de Assist. a Psicop. do Estado de São Paulo, 16:33-37, 1951. 9. SCHNEIDER, K. - Problemas de Patopsicologia y Psiquiatria Clinica. Trad. castelhana, Ed. Morata, Madrid, 1948. 10. SILVEIRA, A. Classificação nacional das doenças mentais. Arq. da Assist. a Psicop. do Estado de São Paulo, 9:73-98, 1944. 11. SILVEIRA, A. - Psicoses degenerativas. Estados crepusculares episódicos (Kleist): cinco observaçóes pessoais. Resumo em memorial para concurso à Docência Livre, São Paulo, 1941, pág. 43. 12. VIZZOTTO, S. - Heredologia nas psicoses degenerativas. Rev. Paulista Med., 39:390-391, 1951. 13. VIZZOTTO, S. - As psicoses degenerativas de Kleist. Rev. Paulista Med., 44:432-435, 1954. 